\title{
Nutrient and Microbial Reduction Properties in Pervious Composites for Blackwater Treatment
}

\author{
Peter Owusu-Antwi, Richard Buamah, Isaac Slase Kuwornu, Helen Essandoh \\ Kwame Nkrumah University of Science \& Technology, Kumasi, Ghana \\ Esi Awuah \\ University of Energy \& Natural Resources, Sunyani, Ghana \\ Kweku Akuam Anno \\ Biological Filters \& Composters Limited (BIOFILCOM), Accra, Ghana
}

\begin{abstract}
The focus of this experiment was to compare the treatment performance of nutrient and microbial reduction in granite (GR), shredded polyethylene terephthalate (SP) and palm kernel shell (PKS) composites after solid/liquid separation of blackwater. Laboratory tests were conducted on replicated specimens of the GR, SP, and PKS pervious composites and the mechanisms of microbial reductions and nutrient transformation in blackwater treatment investigated after filtration. Six cylindrical specimens measuring $110 \mathrm{~mm} \times 100 \mathrm{~mm}$ and made from the GR, SP, and PKS were used to determine the physical and hydrologic properties (density and permeability) of the specimens. Additional six pervious specimens measuring $0.3 \mathrm{~m} \times 0.3 \mathrm{~m} \times 0.05 \mathrm{~mm}$ were used for the solid/liquid separation of blackwater. Blackwater was first infiltrated through a layer of coir fibre and net lining and then run through each pervious composite specimen. Nutrient (ammonium, nitrate, nitrite, total nitrogen, and total phosphorus) and microbial (Escherichia coli and coliforms) analyses were conducted on the effluent from the specimens and compared. The GR, SP, and PKS particle sizes were seen to be uniformly graded and similar. The composite specimens did not have significant effects on the nutrient transformations and removal of organic matter but for total phosphorus. However, escherichia coli and other coliforms's growth were limited in the SP. Hydrophobic interactions between the SP composite and microbial cells of the microbes could have promoted attachment and limited their growth. It was observed that the mean $\mathrm{pH}$ in the effluent filtered through the composites was higher than in the influent partly due to the availability of calcium carbonate in the cement. The study suggests that the SP composite is a promising alternative to the GR composite for the reduction of microbial constituents in blackwater vis-a-vis its light-weight compared to the other pervious composites.
\end{abstract}

Keywords: Biofil, removal efficiency, solid/liquid separation, vermicomposting, PET composite

\footnotetext{
* Acknowledgements: The authors would like to extend thanks to the Bill and Melinda Gates Foundation.

Peter Owusu-Antwi, Ph.D. fellow, Dept. of Civil Engineering, Kwame Nkrumah University of Science \& Technology, Kumasi, Ghana.

Richard Buamah, Ph.D., Dept. of Civil Eng., Kwame Nkrumah University of Science \& Technology, Kumasi, Ghana. Isaac Slase Kuwornu, MSc., Dept. of Civil Eng., Kwame Nkrumah University of Science \& Technology, Kumasi, Ghana. Helen Essandoh, Ph.D., Dept. of Civil Eng., Kwame Nkrumah University of Science \& Technology, Kumasi, Ghana.

Esi Awuah, professor, Ph.D., Dept. of Civil Eng., University of Energy \& Natural Resources, Sunyani, Ghana.

Kweku Akuam Anno, Biological Filters \& Composters Limited (BIOFILCOM), Accra, Ghana.

Correspondence concerning this article should be addressed to Peter Owusu-Antwi, Dept. of Civil Engineering, KNUST, Kumasi, Ghana.
} 


\section{Introduction}

Pervious composite, with its unique infiltration properties, could be beneficial when used as a treatment component for wastewater treatment (Luck, Workman, Higgins, \& Coyne, 2006). Pervious composites consist of Portland cement, uniform sized coarse aggregate, and water. Eliminating fine aggregate in the mix gives the composite void spaces between the coarse aggregate particles and allows for rapid water flow through the composite (Ghafoori \& Dutta, 1995). Over the years, storm water has been the driving forces in the research and development of pervious composite (Luck \& Workman, 2007). Effective solid/liquid separation can be very beneficial in treating wastewater because chemicals, nutrients, and pathogens can adsorb to solid particles in the wastewater stream (USDA-NRCS, 1997), but there have been very little studies on the use of pervious composites in blackwater treatment. On-going research has been conducted on wastewater-purification potential of pervious composite. One study examined the growth of microorganisms within pervious composite by observing the consumption of the dissolved oxygen (Sung-Bum \& Mang, 2004) in runoff. Another evaluated the reduction of total nitrogen and total phosphorous in the pervious composite. The study also demonstrated that the pervious composite was successful at removing total nitrogen and total phosphorus from water samples (Sung-Bum \& Mang, 2004). Additionally, pervious composite has been applied in the treatment of runoff from an animal feeding operation where grooved composite floor systems with perforations were tested for use in cattle buildings in the Netherlands (Swierstra, Braam, \& Smits, 2001). Studies measuring the ability of pervious composite to perform solid/liquid separation in blackwater treatment have not been conducted.

This study forms part of a larger research on the Biofil Toilet Technology (BTT) and seeks to further the study of pervious composite for potential uses in the treatment of household blackwater. The BTT is a blackwater treatment unit with a volume capacity of 0.65 cubic metre. The technology uses aerobic processes for decomposition of faecal matter and other organic components. It has a porous composite filter (PCF) for rapid solid-liquid separation of blackwater. Solids remain in the box and are broken down by the action of earthworms and microbes. Effluent after solid-liquid separation is discharged into the sub-surface soil via a drain field (Figure 1).

The main objective of the study was to compare the removal capacity of nutrients and pathogens by three different pervious composites in blackwater during different solid/liquid separation.

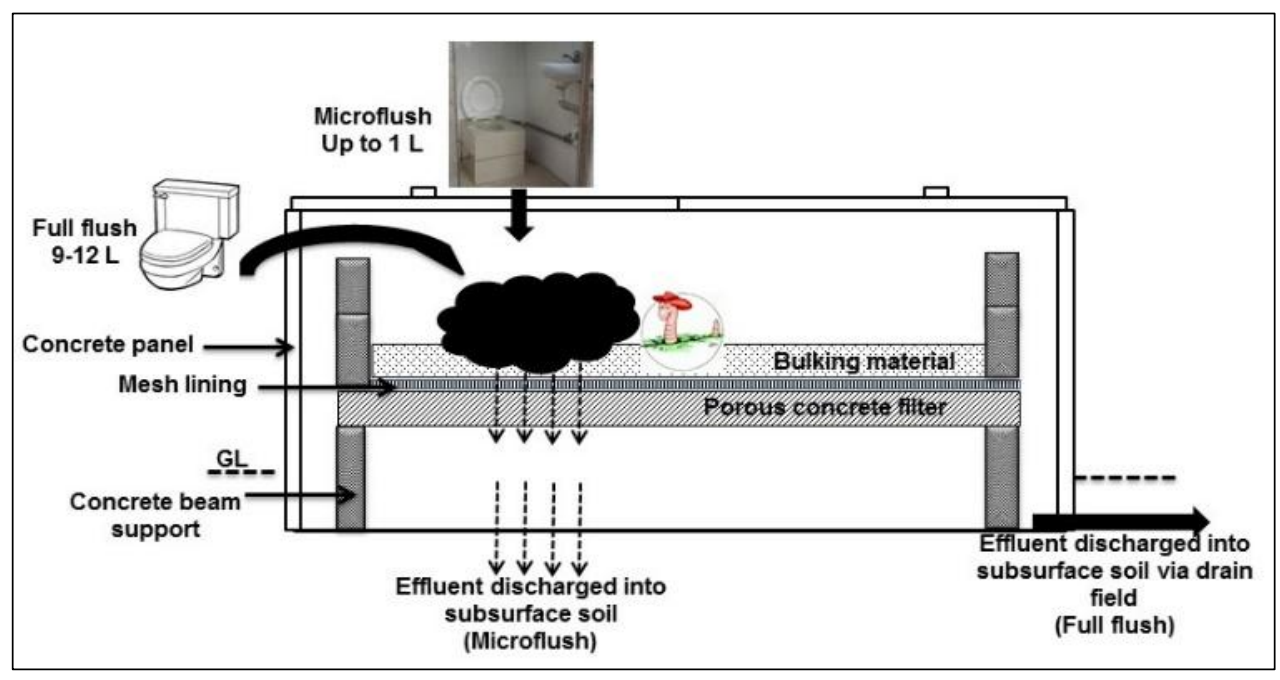

Figure 1. Schematic of the BTT. 


\section{Research Methods}

\section{Composite Samples}

The pervious composite specimens used in this study comprised the Palm Kernel Shells (PKS), shredded Polyethylene Terephthalate bottles (SP) and 1/4 inch Granite Chippings (GR). The effective aggregates sizes of the specimens used for the testing were $3.41 \mathrm{~mm}, 4.8 \mathrm{~mm}$, and $4.9 \mathrm{~mm}$ respectively. PKS and SP were crushed with grinding machines while the particle size of GR was as produced by the quarry. Sieve analysis was conducted on the aggregates using AASHTO T27 (2006) and BS 812 part 103 (1985) standards. Six cylindrical specimens measuring $110 \mathrm{~mm} \times 100 \mathrm{~mm}$ were produced and used for analysis of the physical and hydrologic properties (density and hydraulic conductivity). Another six pervious composites measuring $0.3 \mathrm{~m}$ in length, $0.3 \mathrm{~m}$ in width, and $0.05 \mathrm{~mm}$ thick were produced and used for production of effluent that were subsequently tested. The pervious concrete was placed by hand in wooden forms and compacted using a hand trowel to achieve a final compacted height and cured for 14 days as per ASTM C192 and BS 1881 part 113 (1983). A mix ratio of 1:3 was used with a water-cement (w/c) ratio of 0.35 . Ordinary Portland cement of class $32.5 \mathrm{R}$ was used in all mixes.

\section{Test Methods}

The bulk density $\left(\mathrm{kg} / \mathrm{m}^{3}\right)$ of each specimen was calculated by dividing the weight of the specimen by the respective volume. A constant-head permeameter designed in the laboratory was used to measure the permeability as described by Luck and Workman (2007).

The permeability of each specimen was calculated by dividing the recorded flow rate by the surface area for each specimen.

Effluent testing was conducted using $500 \mathrm{~mL}$ of effluent through the pervious composites by running blackwater (150 g solids and 3.3 litres) through a $30.5 \mathrm{~mm}$ layer of coir fibre and non-reactive mesh screen. The effluent was tested for: $\mathrm{pH}$, temperature, ammonium $\left(\mathrm{NH}_{4}{ }^{+}\right)$, nitrate $\left(\mathrm{NO}_{3}{ }^{-}\right)$, nitrite $\left(\mathrm{NO}_{2}{ }^{-}\right)$, Total Nitrogen (TN), Total Phosphorus (TP), E.coli, and other coliforms. All analyses were performed in accordance with the Standard Methods for the Examination of Water and Wastewater (20th ed.) (APHA, 1998). Membrane filtration and pour plate technique and microscopic examination and counting were used in monitoring the microbial populations and helminth eggs in the effluent samples respectively.

\section{Statistical Analysis}

$T$-tests were utilized to determine whether there were significant differences in the values of the parameters tested. The $t$-tests were conducted using the two-tailed least significant difference (LSD) and differences were considered significant at an alpha value equal to $0.05(p \leq 0.05)$ (Montgomery, 1997).

\section{Research Results and Discussions}

\section{Particle Size Distribution and Density}

The grading curves for PKS, SP, and GR resulted in a uniformity coefficient $\left(C_{U}\right)$ of $1.625,1.848$, and 1.510 with a corresponding effective aggregate particle size of $4.8 \mathrm{~mm}, 3.41 \mathrm{~mm}$, and $4.9 \mathrm{~mm}$ respectively. The result suggests the PKS, SP, and GR were uniformly graded. A correlation matrix performed on the three specimens indicated strong correlation amongst them with the highest of 0.978 recorded between PKS and GR. A correlation value of 0.879 was also recorded between SP and GR. A p-value of 0.9563 (95\% confidence level) indicated the statistically insignificant variation is amongst the specimens. This strongly indicates that the 
particle sizes of PKS were close to GR followed by the SP.

The densities of the pervious composite specimens were $781.45 \mathrm{~kg} / \mathrm{m}^{3}, 1,171.3 \mathrm{~kg} / \mathrm{m}^{3}$, and $1,944.34 \mathrm{~kg} / \mathrm{m}^{3}$ for SP, PKS, and GR respectively. According to a study conducted by Luck et al. (2006), the result of the study indicated density ranges of $1,739-2,023 \mathrm{~kg} / \mathrm{m}^{3}$. Presently, the BTT uses GR as the pervious concrete filter. The SP being approximately 2.5 times and 1.5 times lighter than both the GR and PKS when used as a substitute could influence the cost and ease of transportation.

\section{Permeability}

The permeability of the pervious composite specimens ranged between 0.0352 and $0.0392 \mathrm{~cm} / \mathrm{s}$. The GR aggregate had a significantly lower permeability than the SP $(0.0372 \mathrm{~cm} / \mathrm{s})$ and PKS aggregates. The regression model for specimen density and permeability $\left(R^{2}=0.4642\right)$ suggests that if the density of the composite mixture were to increase, the permeability would be greatly reduced. The loss of permeability could be attributed to the lack of interconnected voids in the mixture at high densities as suggested by Luck et al. (2006).

\section{Effluent Testing}

There was no significant variation $(p=0.1662)$ in $\mathrm{pH}$ values throughout the experiment as a result of filtering the effluent through the pervious composite. The $\mathrm{pH}$ in the blackwater (BWI) and coir fibre (FF) was similar. The $\mathrm{pH}$ increase from using the pervious composite for filtration (Figure 2) was most likely the result of available calcium carbonate in the cement (Luck \& Workman, 2007). Additionally, the decomposition of organic fractions of wastewater, mainly by microbes in water, produces some species of mineralized organic materials $\left(\mathrm{CO}_{3}{ }^{2-}, \mathrm{NH}_{4}{ }^{+}\right.$, and $\left.\mathrm{NO}_{3}{ }^{-}\right)$which play an important role in shifting of $\mathrm{pH}$ scale (Suthar \& Tomar, 2011). The high urea content in urine which forms a major part of blackwater may also have contributed to basic nature of the effluent (Owusu-Antwi, 2015).

There was a general increase in the conductivity and dissolved solid concentration as the effluent run through the composite specimens (Figure 2). Electrical conductivity indicates solute concentrations (e.g. nitrates) found in the effluent filtered with pervious composite (Luck \& Workman, 2007). Adsorption plays a key role in the removal of dissolved contaminants during filtration in a medium (Schmoll, Howard, Chilton, \& Chorus, 2006). Due to the high hydraulic conductivity of the composite specimens, there was low contact time to initiate any such adsorptive mechanisms and thus the high concentrations in the conductivity of the effluent. The filtration through the coir fibre and composite specimens may have also leached solute into the effluent resulting in the increase in the conductivity of the effluent.

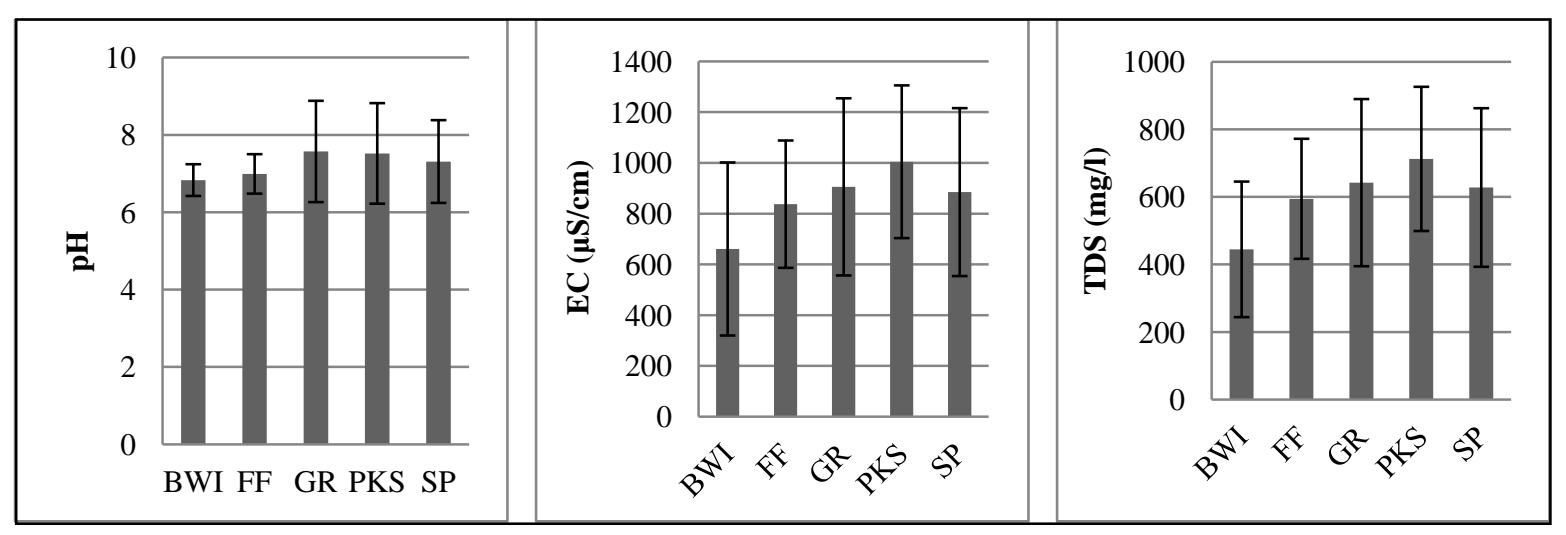

Figure 2. Effluent pH, EC, and TDS levels of blackwater and coir fibre compared with composite specimens. 
There was a significant increase in BOD and COD in the effluent filtered through the coir fibre (Figure 3). A separate test run using only distilled water through the coir fibre ascertained the leaching of solute in the effluent. Additionally, one-way ANOVA showed a high variation in BOD concentration $(p=3.47 \times$ BOD concentration of the BWI and the effluent from the FF. This indicates high organic constituents in the coir fibre leaching into the effluent. However, the composite specimens did little in reducing the concentration of BOD of the coir fibre effluent filtered through them.

Similarly, there was a significant increase in the TSS in the effluent filtered through the coir fibre. The reduction in TSS in the effluent filtered through all composite specimens was statistically insignificant $(p=$ 0.730). Suspended solids are usually removed by filtration through upper soil layers with very low permeability and the largest part is organic nature in form of volatile suspended solids (Idelovitch, Icekson-Tal, Avraham, \& Michail, 2003). This could suggest the reason for the low reduction in TSS in the effluent filtered through the pervious composites. It is important to note that there was reduction in the TSS by the GR and SP composites (Figure 3).

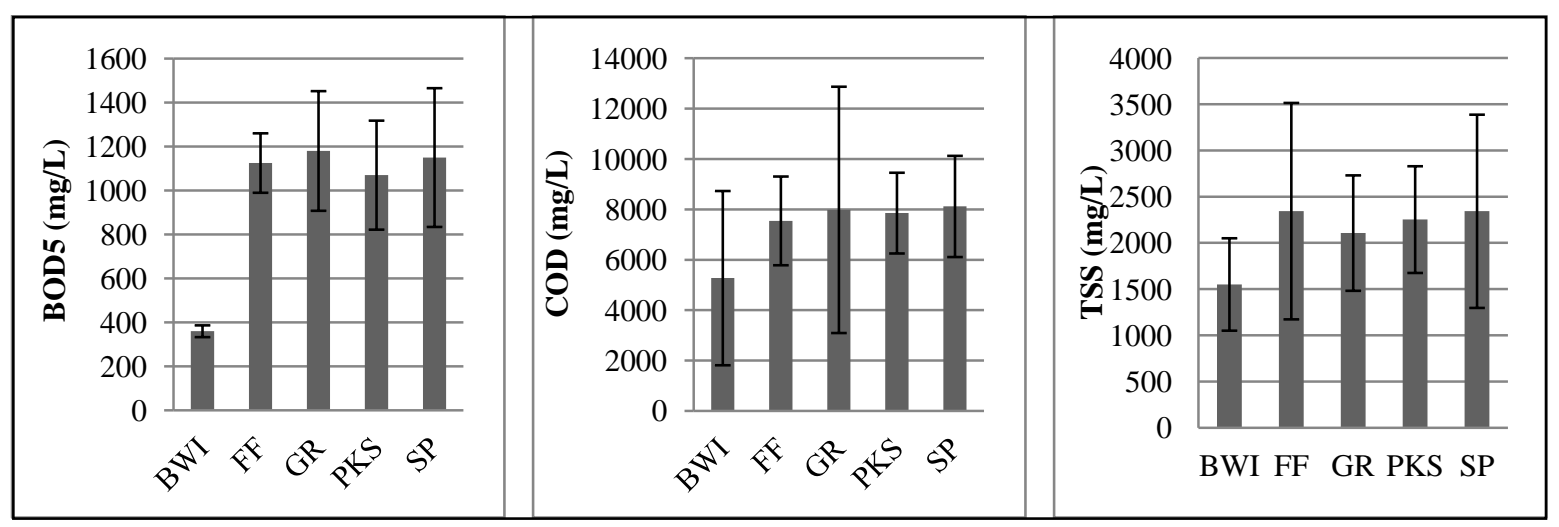

Figure 3. Effluent BOD, COD, and TSS levels in blackwater and coir fibre compared with composite specimens.

Generally, the pervious composite was not consistent in terms of $\mathrm{N}$ reduction (Figure 4). There was no significant difference between the concentrations of nutrients in the blackwater influent and in the effluent from any of the filters ( $p$ value ranged from 0.302 to 0.9918 ) even though some reductions were observed in the GR and SP. It is possible that the high permeability of the specimens did not allow for much interaction between the coir fibre effluent and the composite. Sato, Iwashima, Matsumoto, Wakatsuki, and Masunaga (2010) in their study on the reduction in ammonia through its possible adsorption unto the filter media of their packed beds indicated the influence of low contact time in limiting this phenomenon. Previous research studied on pervious composite for the potential removal of TN concluded that the pervious composite was capable of reducing TN levels over several days (Sung-Bum \& Mang, 2004). The mechanism responsible for the reduction of $\mathrm{TN}$ was believed to be due to microorganisms attached to the pervious composite. Filtration using the pervious composite resulted in significantly lower levels for TP. Particulate trapping and absorption by the pervious composite were most likely responsible for TP reduction (Luck \& Workman, 2007).

Effluent from the PKS gave the highest count of E.coli of $26 \times 10^{8} \mathrm{cfu} / 100 \mathrm{~mL}$ with corresponding non-faecal coliform count of $9 \times 10^{8} \mathrm{cfu} / 100 \mathrm{~mL}$ and $12 \times 10^{8} \mathrm{cfu} / 100 \mathrm{~mL}$ respectively. SP yielded the least coliform concentration with an E.coli concentration of $6 \times 10^{8} \mathrm{cfu} / 100 \mathrm{~mL}$ and other coliform concentration of 4 $\times 108 \mathrm{cfu} / 100 \mathrm{~mL}$ (Figure 5). One-way ANOVA showed a very high variation in the counts of E.coli colony 
forming units $(\mathrm{cfu})\left(p=8.334 \times 10^{-12}\right)$ in the effluent filtered through the composites. There was significant variation between the E.coli population of the BWI and the effluent from $\operatorname{FF}(p=0.000373)$.

There was also a significant variation between E.coli numbers between the effluent from FF and effluent from SP composite $\left(p=4.154 \times 10^{-5}\right)$. Hydrophobic interactions between filtering media particles and microbial cells of the microbes could have promoted attachment (Schaefer, Ustohal, Harms, Stauffer, Dracos, $\&$ Zehnder, 1998) and thus, the reduction in the counts.

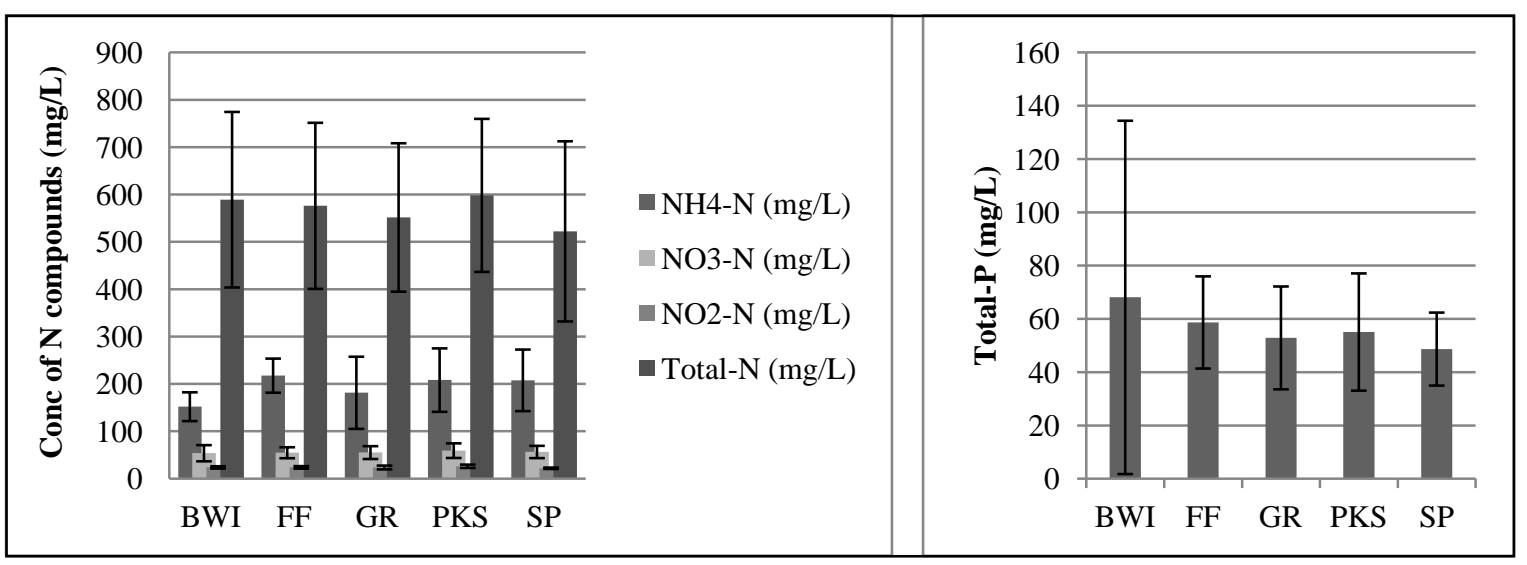

Figure 4. Effluent nutrient levels in blackwater \& coir fibre compared with composite specimens.

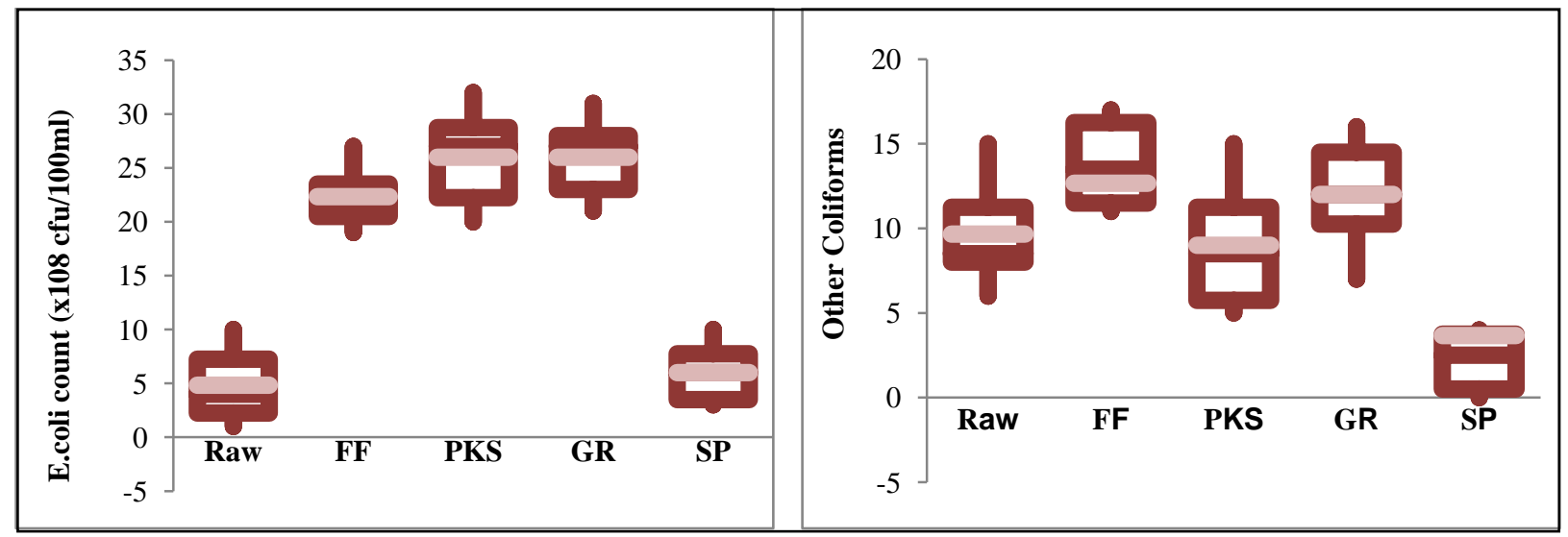

Figure 5. Effluent pathogen levels in blackwater \& coir fibre compared with composite specimens.

\section{Conclusions}

The test results suggest that the Palm Kernel Shells, Shredded Polyethylene Terephthalate, and Granite Chippings particle sizes are uniformly graded and similar thus can be substituted in their use as pervious composites for solid/liquid separation in blackwater treatment. Further work should be done to ascertain their respective efficiencies in solid-liquid separation. The permeability of the composites was heavily influenced by their densities with an increase in the densities resulting in an ensuing decrease in permeability. Future research should consider long-term testing to determine how the pervious composites behave over time when exposed to continuous flushing with blackwater. The mean $\mathrm{pH}$ in the effluent filtered through the composites was higher than in the influent. The $\mathrm{pH}$ increase from using the pervious composite for filtration was most likely the result of available calcium carbonate in the cement and the presence of some species of mineralized organic materials $\left(\mathrm{CO}_{3}{ }^{2-}, \mathrm{NH}_{4}{ }^{+}\right.$, and $\left.\mathrm{NO}_{3}{ }^{-}\right)$. There was a general increase in the conductivity and TDS concentration in the coir 
fibre effluent and effluent as a resulting of filtration through the composites, indicating the leaching of solute particulates. For most of the parameters, there were no consistent significant differences in effluent values through the composites. However, TP and the pathogens showed significant differences in the effluent values through the composites. The pervious composite was not consistent in terms of $\mathrm{N}$ reduction. There was no significant difference between the concentration of nutrients in the blackwater influent and in the effluent from any of the filters. BOD and COD generally increased due to the leaching of organic constituents from the coir fibre through the composites. Some reduction of parameters in the effluent could also be due to adsorption or retention of water in the pervious composite and this could be increased by increasing the contact time. There was a significant variation between E.coli number between the effluent from FF and effluent from SP composite. Hydrophobic interactions between the SP composite and microbial cells of the microbes could have promoted attachment and limited their growth.

\section{References}

AASHTO T 27-Standard Method of Test for Sieve Analysis of Fine and Coarse Aggregates. (2006). American Association of State and Highway Transportation Officials, Standard Specifications for Transportation Materials and Methods of Sampling and Testing, Washington, D.C.

APHA (American Public Health Association). (1998). Standard methods for the examination of water and wastewater (20th ed.). In L. S. Clesceri, A. E. Greenberg, and A. D. Eaton (Eds.). Washington, D.C., American Public Health Association, American Water Works Association, and Water Environment Federation.

BS 812-103. (1985). Testing aggregates. Method for Determination of Particle Size Distribution. Sieve Tests.

Ghafoori, N. D., \& Dutta, S. (1995). Development of no-fines concrete pavement applications. J. Transportation Eng., 121(3), 283-288.

Idelovitch, E., Icekson-Tal, N., Avraham, O., \& Michail, M. (2003). The long term performance of soil aquifer treatment for effluent reuse water science and technology. Water Supply, 3(4), 239-246.

Luck, J., \& Workman, S. R. (2007). Effects of pervious concrete on potential environmental impacts from animal production facilities (M.Sc. thesis). Department of Biosystems and Agricultural Engineering, University of Kentucky, Lexington, Kentucky, p. 61.

Luck, J. D., Workman, S. R., Higgins, S. F., \& Coyne, M. S. (2006). Hydrologic properties of pervious concrete, plant and soil sciences faculty publications. Paper 19.

Montgomery, D. C. (1997). Design and analysis of experiments. New York, N.Y.: John Wiley and Sons.

Owusu-Antwi, P., Buamah, R., Essandoh, H., Molla, A. S., Awuah, E., \& Anno, A. A. (2015). The potential of subsurface infiltration for the treatment of biofil toilet technology effluent. Management Studies, 3(11-12), 281-299.

Sato, K., Iwashima, N., Matsumoto, T., Wakatsuki, T., \& Masunaga, T. (2010). Wastewater treatment processes and mechanisms of organic matter, phosphorus, and nitrogen removal in a Multi-Soil-Layering system. Paper presented on the 19th World Congress of Soil Science, Soil Solutions for a Changing World, 1-6 August 2010. Brisbane, Australia. Published on DVD.

Schaefer, A., Ustohal, P., Harms, H., Stauffer, F. T., Dracos, T., \& Zehnder, A. J. B. (1998). Transport of bacteria in unsaturated porous media. Journal of Contaminant Hydrology, 33, 149-169.

Schmoll, O., Howard, G., Chilton, J., \& Chorus, I. (2006). Protecting groundwater for health: Managing the quality of drinking water sources. WHO drinking-water quality series. London: IWA Publishing.

Sung-Bum, P., \& Mang, T. (2004). An experimental study on the water-purification properties of porous concrete. Cement Concrete Res., 34, 177-184.

Suthar, S., \& Tomar, P. (2011). Urban wastewater treatment using vermi-biofiltration system. Desalination, 282, 95-103.

Swierstra, D., Braam, C. R., \& Smits, M. C. (2001). Grooved floor system for cattle housing: Ammonia emission reduction and good slip resistance. Applied Eng. in Agric, 14(1), 85-90.

USDA-NRCS (US Department of Agriculture-Natural Resources Conservation Service). (1997). Water quality and agriculture: Status, conditions, and trends (Working Paper \#16). Washington, D.C. 